\title{
Psicologia Social e Formas de Vida Rural no Brasil ${ }^{1}$
}

\author{
Francisco José Batista de Albuquerque ${ }^{2}$ \\ Universidade Federal da Paraíba
}

\begin{abstract}
RESUMO - A psicologia tem se voltado preferencialmente a estudar os fenômenos psicossociais do ambiente urbano. No Brasil, onde aproximadamente um quarto de sua população reside em municípios com menos de 20000 (vinte mil) habitantes, é importante que esta dimensão deva ser incluída na pauta de trabalhos e de estudos da psicologia brasileira. As razões para isto prendem-se a distintas causas, como o crescimento desordenado da urbanização no país, a emergência dos problemas sociais urbanos, e o crescimento da importância dos segmentos industriais e de serviços em detrimento da economia agrária. Também se pretende chamar a atenção para a necessidade de entender o rural como distinto do agrário e para a grande possibilidade de opções de trabalhos e pesquisas que podem ser realizados.
\end{abstract}

Palavras-chave: Psicologia social; desenvolvimento rural; políticas públicas.

\section{Social Psychology and Rural Life in Brazil}

\begin{abstract}
Psychology is mainly concerned about the study of urban social phenoma. In Brazil, where about a quarter of its population lives in towns with less than 20.000 (twenty thousand) inhabitants, it would be important to include this dimension in the Brazilian psychological research. There are several reasons to do this such as the increasing importance of the industrial and the services sector in detriment of the agrarian economy. Another reason is to attract attention to the need of understanding the differences between the rural and the agrarian, and also to enlarge the scope of the studies that can be done.
\end{abstract}

Key words: Social psychology; rural development; public policies.

Ao tratar de um aspecto novo, em um campo tão conhecido por todos nós como é o da psicologia, gostaria de lembrar que, muitas vezes, é preciso chamar a atenção para certos detalhes que geralmente, de tão conhecidos passam despercebidos. Por isto, parece oportuno o comentário que Kurt Lewin (1995) nos brindou quando tratava da inserção da psicologia na vida real, na vida da comunidade, dizia ele:

Seria muito desastroso se a tendência para a psicologia teórica fosse enfraquecida pela necessidade de lidar com grupos naturais ao estudar determinados problemas de psicologia social. Não deveríamos deixar de notar, entretanto, o fato de que este desenvolvimento oferece grandes oportunidades bem como ameaças à psicologia teórica. A maior limitação da psicologia aplicada está no fato de que, sem auxílio teórico adequado, teve que seguir o método custoso, improdutivo e limitado de ensaio e erro. Muitos psicólogos trabalhando hoje num campo aplicado estão plenamente conscientes da necessidade de uma cooperação entre psicologia teórica e aplicada. Isto pode ser conseguido em Psicologia, como foi em Física, se o teórico não olhar para problemas aplicados com medo dos problemas sociais, e se o psicólogo aplicado perceber que não existe nada mais prático quanto uma boa teoria (p. 191).

Peço a ajuda de Lewin, porque ele foi dos primeiros a romper com o isolamento da psicologia, trazendo-a para mais

1 Parte deste trabalho foi apresentado no I Congresso Norte Nordeste de psicologia, em Salvador, Bahia. Agradeço as sugestões do Professor Dr. Oswaldo H .Yamamoto, no momento em que o isento de quaisquer responsabilidades sobre as possíveis deficiências deste artigo.

2 Endereço: Departamento de Psicologia, Universidade Federal da Paraíba, Cidade Universitária. CEP.: 58059-090 - João Pessoa PB. Email: frajoba@uol.com.br perto dos problemas sociais. Foi de uma importância tal que, hoje, poucos psicólogos negam estudar ou desenvolver ações visando à aplicação dos nossos conhecimentos a atividades próximas à realidade cotidiana. Felizmente, esta parece ser uma discussão superada. Entretanto, outra questão aparece quando tratamos de estudar e aplicar nossos conhecimentos sobre a realidade brasileira. Uma revisão nos anais dos últimos congressos poderá nos mostrar que, embora pratiquemos uma psicologia aplicada ao Brasil e ao brasileiro, com sua cultura, sutilezas e nuanças próprias, realizamos uma psicologia urbana. É nossa intenção doravante trazer à baila o porquê, do nosso ponto de vista, isto ocorre em um país que tem a imensidão de continente. Atualmente, dos 5507 municípios brasileiros, 4089 possuem menos de 20000 habitantes, ou seja, $74,2 \%$ ou $3 / 4$ do total dos municípios brasileiros podem ser considerados como de características rurais abrigando uma população de 31845211 (trinta e um milhões e oitocentos e quarenta e cinco mil e duzentos e onze) habitantes, correspondendo a $18,77 \%$ da população total. (www.ibge.net/ibge/estatística/população/censo2000/ tabelabrasil111.shtm).

Então, por que não estudamos essa parte da população? Por que preferimos analisar os aspectos urbanos e não também os daqueles habitantes da zona rural brasileira?

\section{Olhar Urbano e Formas de Vida Rural}

Algumas hipóteses nos surgem. A primeira delas, a de que somos levados a estudar mais os problemas que conhecemos, que nos cercam. Como os psicólogos são fruto do desenvolvimento e da migração do campo para as cidades, 
nos deparamos mais com estes problemas do que com os que os originam, como a organização fundiária e as políticas públicas para o meio rural. Os fenômenos migratórios internos geraram uma grande mudança social na medida em que as cidades, e aqui no Brasil, algumas cidades, foram efetivamente o pólo de atração de todo este contingente humano, com todas as conseqüências de desenraizamento familiar, marginalização e demais sequielas sociais de todos conhecidas. As cidades se transformaram em grandes concentrações habitacionais que, por sua vez, demandam uma aplicação imediata da psicologia, pois ai estão as grandes empresas, os grandes bolsões de miséria e os maiores problemas resultantes da marginalização como a delinqüência, a drogadição e um grande etc.

Por outro lado, a metodologia e os instrumentos que são utilizados na psicologia e na psicologia social em particular, é um processo baseado e pensado para a população urbana essa é uma variável nunca citada na hora de generalizar os resultados. As características próprias do ambiente rural, provavelmente requerem uma maneira, uma metodologia mais adequada a ela a partir da avaliação das teorias que foram desenvolvidas para ambiente urbano (Albuquerque, 2001).

Porém, apenas isto bastaria para explicar tudo? Parecenos que não. Devemos também olhar para o processo de desenvolvimento brasileiro e analisarmos que a contribuição do ambiente rural para com o PIB (Produto Interno Bruto) tem decrescido ao longo dos últimos anos, e é natural que assim seja. Deixamos de ser um país agrário para passarmos a país de produção industrial e de serviços. Dessa maneira, àquelas atividades que antes importavam pelas suas conseqüências sociais e econômicas, agora não mais se presta a devida atenção.

Que questões isso nos coloca? Pois a de vivermos em um país que optou por um modelo de desenvolvimento agrário através do financiamento e incentivo à agricultura de larga escala, em detrimento da agricultura familiar. Este não foi o caso de outros países que obtiveram um elevado nível de desenvolvimento mantendo a agricultura familiar em ponto privilegiado. Veja-se como exemplo os países europeus, onde a agricultura familiar foi a âncora onde se assentou grande parte do processo de seu desenvolvimento. Os Estados Unidos da América, país tido como essencialmente patronal, tem na sua agricultura familiar a base histórica em que foi processado o seu desenvolvimento sendo que grande parte de sua produção agrária tem origem familiar (Ribeiro, 1978).

Nos últimos 20 anos, a produção de grãos no Brasil mantém-se no patamar dos 90 milhões de toneladas / ano. Essa é uma marca histórica que, por mais esforços que as políticas de incentivo - que são cada vez menores, diga-se de passagem - procurarem alterar, não conseguem sair desse parâmetro. Além disso, como conseqüência desse modelo, por excelência patronal e concentrador de capital, chegamos a uma situação de grande disparidade de renda e de qualidade de vida entre nossa população. Tivemos uma migração elevada, em um curto espaço de tempo, e para poucas cidades, gerando bolsões de concentrações humanas em condições de vida muito precárias. Assim, perdemos uma estrutura de desenvolvimento no campo, sem gerar uma fonte de sustentação nas cidades. Adicionalmente, é importante frisar que no Brasil, segundo Ieno Neto e Bamat (1998) em torno de $50 \%$ da produção dos alimentos básicos e da produção animal é realizada na propriedade de exploração familiar.

O mundo rural deixou de ter, como única ou principal fonte de desenvolvimento e renda, a produção agrária. Esse fato, que se verificou nos países mais desenvolvidos (Garcia Sanz, 1999), chega agora com muita força em nosso país. As pequenas indústrias, o comércio, os serviços e as aposentadorias constituem hoje os principais vetores de recursos para os pequenos municípios brasileiros. O rural, ou a sociedade rural em uma primeira aproximação seria uma forma de vida que abarca todos os membros que vivem em uma coletividade rural, trabalham na agricultura ou em outras atividades diferentes. Formaria também parte dessa coletividade uma população ativa, cada vez mais numerosa, que vive ou reside em uma localidade rural ainda que diariamente se translade a outras localidades, rurais ou urbanas, para realizar suas atividades. Antes, era o agrário que predominava no rural, não apenas como fonte de riqueza econômica, mas também como fonte de poder político. O prefeito e os vereadores ou eram pessoas ligadas diretamente à agricultura, ou então recebiam seu apoio e dela dependiam. Agora esse poder está amplamente minimizado, posto que a fonte de renda no mundo rural não é mais exclusivamente agrária. Portanto, ao planejar as políticas públicas, deve-se estar atento a esta questão, no sentido de valorizar no rural, atividades, serviços e procedimentos que não se prendam exclusivamente ao agrário, como é freqüente acontecer.

Por outro lado, não é possível analisar esses aspectos sem considerar o enorme avanço em termos de conhecimento que foram desenvolvidos em função do ambiente agrário nos últimos anos. Da clonagem de vegetais e animais a pesticidas e fungicidas; dos cultivos hidropônicos à melhoria dos solos, muito conhecimento novo foi produzido. Conhecimento técnico, necessário, porém não suficiente para auxiliar no salto de qualidade de vida para a população do Brasil.

Todo este avanço tecnológico foi dirigido à grande propriedade, deixando mais uma vez à margem a agricultura familiar. Esforços têm sido desenvolvidos nessa direção. As Empresas Brasileiras de Extensão Agrária - EMATER's têm realizado muitos trabalhos, através dos seus técnicos, para levar conhecimentos aos pequenos agricultores. Debalde, posto que, fruto dessa política privilegiadora do grande produtor, não existe disseminado entre os técnicos uma tecnologia de produção voltada para atender a essa população. De acordo com Mascareño (1999), os técnicos são instruídos e formados desde as universidades, em uma perspectiva de otimizar a agricultura de larga escala, estando despreparados para atender aqueles que fogem ao padrão da grande empresa.

Atualmente, falar do agro no Brasil implica falar também no Movimento Nacional dos Trabalhadores Rurais Sem Terra (MST) e no processo de reforma agrária. Conforme os 
últimos dados disponíveis pelo INCRA (Instituto Brasileiro de Colonização e Reforma Agrária) foram criados, em todo o território nacional, cerca de 2500 assentamentos, atendendo nos últimos seis anos aproximadamente 550.000 (quinhentas e cinquenta mil) familias (www.incra.gov.br) atingindo uma população estimada de mais de dois milhões de pessoas. São números grandes, proporcionais ao tamanho dos problemas do Brasil nessa área. E nós, psicólogos, que temos dito ou a dizer sobre isto? Poucas são as pesquisas na área de psicologia que buscam conhecer melhor esse universo. Até mesmo, para evitar-se mal entendidos, seria importante que informássemos a este público do que somos capazes de lhes oferecer, como trabalhos em avaliação de políticas públicas, na área das organizações, sobre cooperativismo e associacionismo, resolução de conflitos, transferência de tecnologias, saúde mental e bem-estar psicológico, etc.

\section{Identidade e Movimentos Sociais}

O processo psicológico de construção da identidade social tem sido campo fértil de estudos na psicologia social tradicional, e supõe não apenas a inclusão de uma dimensão de caráter mais social nos estudos sobre as relações intergrupais e sobre a identidade, mas também, e principalmente, que em seu esquema teórico é impossível o estudo de um destes campos sem referência ao outro (Morales, Paez, Deschamps \& Worchel, 1996). Desses estudos, resulta o papel ativo que cada um representa na construção dessa sua identidade. As crenças e expectativas de cada indivíduo concorrem para a formação das normas e pautas de conduta dos grupos, que por sua vez estruturam toda a complexa trama do ambiente social. A necessidade de símbolos, ou mesmo, a mudança de comportamentos operados a partir da introdução de variáveis como a simples escolha de um de dois quadros, como demonstram as pesquisas sobre os grupos mínimos ou o estabelecimento de metas a serem alcançadas conjuntamente ou individualmente, podem fazer a diferença entre sentir-se parte de um grupo ou não. Por outro lado, os movimentos minoritários destacam-se no cenário político, forçando uma resposta da maioria funcional a seus propósitos (Rebolloso, 1994). Nós, psicólogos, detemos esse conhecimento, podemos aplicá-lo a essas circunstâncias ou nos omitimos?

O que dizer então sobre o conhecimento que nos foi proporcionado pelo próprio Kurt Lewin e outros como Sheriff e Moscovici sobre a coesão grupal e os aspectos de liderança, influência de grupos minoritários sobre os grupos majoritários, e a participação democrática? Os movimentos sociais no campo necessitam desse conhecimento, pois freqüentemente, vive a circunstância na qual um grupo de dezenas ou centenas de famílias, depois de passarem alguns meses ou anos acampados em situações precárias, obtêm o acesso à terra. O seu nível de coesão grupal, nestes momentos, era bastante elevado. O inimigo comum era externo ao grupo, e como tal, para ser vencido necessitava da colaboração de todos. Entretanto, passado algum tempo, este nível de coesão tende a enfraquecer, pois os objetivos agora a serem al- cançados dependem mais de metas pessoais ou familiares que de todo o grupo, gerando conflitos internos ao próprio movimento, muitas vezes enfraquecendo ou adicionando dificuldades operacionais a uma conquista duramente realizada (Bonavigo, 1998; Carvalho, 1998; Figueiredo, 1995). Nós, psicólogos, podemos ajudar nesse processo?

E o que dizer sobre as relações entre os assentados e os seus vizinhos? Essas relações são na maioria das vezes tensas e distantes. As diferenças entre o modo de acesso à terra permeiam essas relações dificultando a inserção dos assentados com a comunidade que lhes rodeia. Porém, a finalidade do assentamento é a sua integração na comunidade. $\mathrm{O}$ assentamento terá obtido seu objetivo, na medida em que deixe de se diferenciar da comunidade que o cerca e passe a integrá-la, produzindo e participando do seu dia-a-dia. Para isso, seria necessário que fossem criadas outras condições que possibilitassem e facilitassem essa integração. Contudo, nem por parte dos órgãos governamentais, nem pelos movimentos sociais que atuam com os trabalhadores rurais, se percebe essa preocupação. Será que nós, psicólogos, poderíamos estudar e contribuir com o nosso conhecimento para a melhoria dessas relações?

E o que dizer sobre as organizações agrárias? O processo de modernização agrária do Brasil foi estruturado com base em forte concentração de capital, com ênfase na exportação. Segundo Ianni (1979)

Na lógica do modelo de economia aberta estava tanto a ênfase
na exportação de produtos industrializados, de base não-agrí-
cola, como a exportação de produtos de origem agrícola in-
dustrializados ou não. Daí o empenho dos governos em impul-
sionar toda produção exportável. Ao mesmo tempo que o po-
der público foi levado a favorecer e incentivar a produção e
exportação do setor secundário, também favoreceu e incenti-
vou a produção e exportação do setor primário. Tratava-se e
trata-se de produzir divisas para criar capacidade de impor-
tar tecnologia, insumos industriais e know how, para produ-
zir, para exportar, para criar a capacidade de importar e as-
sim por diante. A acumulação capitalista, acompanhada de
um intenso processo de concentração e centralização do capi-
tal, estava baseada num mercado interno restrito e num mer-
cado externo em expansão (p. 37).

Essa análise realizada em 1979 ainda pode ser lida, não apenas como um retrato histórico, mas como este eixo central de desenvolvimento da economia do país em geral e da economia rural em particular vem se mantendo. Nesse contexto, as organizações cooperativas, ao lado das usinas de açúcar e álcool, além das grandes plantações de soja, foram os instrumentos privilegiados para a implementação dessa política. Porém como funciona esse tipo de organizações? Que trama psicológica envolve os seus membros? Em nossos estudos sobre cooperativas temos encontrado que são organizações bastante diferentes daquelas tradicionais, e que se pautam por uma relação com o Estado de forma a permitir que seus sócios recebam incentivos financeiros, privatizando estes recursos em detrimento dos investimentos públicos nas áreas sociais. Entretanto, a imagem que passam para a população é a de que sejam organizações de 


\section{F. J. B. Albuquerque}

cunho solidário e social Albuquerque (1996), Albuquerque, Clemente e Menezes (1996), Clemente e Albuquerque (1993), Clemente e Albuquerque (1998), Clemente, Albuquerque e Reys (1993). Desconstruir determinados conceitos e aclarar crenças errôneas não é o nosso papel enquanto psicólogos comprometidos com o social?

\section{Educação, Justiça e Cidadania}

E a qualidade de vida na zona rural? E a escola rural? Analisar e comparar aspectos estruturais, funcionais e suas conseqüências comportamentais não é o nosso papel enquanto pesquisadores? Como não desmascarar que o rebotalho da educação está no campo, o que, por sua vez, vai gerar mais miseráveis vivendo como zumbis, pois não encontrarão mais lugar nem na terra, nem nas cidades, restando-lhes apenas o consolo de um lugar ao céu, se é que ali, pobres podem se abrigar. Estudos sobre a avaliação do impacto psicológico de políticas públicas, estudos descritivos dessa realidade, podem ser ferramentas úteis como resgate dessa população marginalizada. Ignácio Martin-Baró (1998), analisando o papel que os psicólogos poderiam desempenhar em relação a situação de miséria permanente dos povos na América Central, considerava suas limitações enquanto agente social para ele mesmo solucionar os problemas estruturais que enfrentam estes povos, para ele, seria incorrer no grave erro do psicologismo, entretanto percebe ações que podem ser desenvolvidas pelos psicólogos e que poderiam ajudar a resgatar a condição de cidadania destes povos, conforme demonstram suas palavras:

Sem dúvida, há uma tarefa importante que o psicólogo deve cumprir e que requer tanto o reconhecimento objetivo dos principais problemas que afetam aos povos centro-americanos, como a definição da contribuição específica do psicólogo em sua resolução. Porque se o psicólogo não é chamado a intervir nos mecanismos sócio econômicos que articulam as estruturas de injustiças, sim é chamado a intervir nos processos subjetivos que sustentam e viabilizam essas estruturas injustas; se não cabe ao psicólogo conciliar as forças e interesses sociais em confronto, sim lhe compete ajudar a encontrar caminhos para mudar os hábitos violentos por hábitos mais racionais; $e$ se não encontra-se sob sua competência a definição de um projeto nacional autônomo, sim pode contribuir para a formação de uma identidade, pessoal e coletiva, que responda as exigências mais autênticas dos povos (p. 176).

Será que nós psicólogos poderíamos estar mais atentos para esses fenômenos, em um país onde cerca de um quinto de sua população vive nessas circunstâncias?

A ausência de programas de saúde, educação e justiça tem repercussões na vida social que vão além daquelas meramente funcionais. São elas que instrumentalizam a rede de dependência da maioria da população em relação a uns poucos aquinhoados, que através do assistencialismo por um lado, e da prepotência por outro, controlam toda a trama social de manutenção da miséria. Precisamos entender as repercussões dessa trama para poder dar o salto de libertação das armadilhas que ai são engendradas. Nada mais po- deroso do que a consciência para permitir o avanço de um povo em direção a sua cidadania, nós psicólogos desenvolvemos um corpo de conhecimento que pode auxiliar neste processo, junto aos marginalizados em geral, e aos que vivem no ambiente rural em particular. Paulo Freire já nos ensinava a força desse poder.

A carência de um sistema de saúde adequado faz com que os habitantes da zona rural necessitem de uma relação personalística com os políticos ou com os "coronéis" locais, sob pena de ver seus filhos, esposas e maridos morrerem por falta de uma ambulância, de um medicamento ou de um hospital (Albuquerque, 1997). Desse modo, o voto, a submissão e a obrigação dos favores, são as mercadorias que eles possuem para manter-se vivos.

Para romper com o ciclo vicioso da dependência pela pobreza, seria importante que cada morador da zona rural tivesse acesso aos serviços básicos de moradia, educação, saúde e justiça, porque é através da presença do Estado nestes setores, que ele pode se livrar da dependência econômica e cultural em que vive. E nós, psicólogos, não podemos dar as costas para esta realidade. $\mathrm{O}$ desenvolvimento e a modernização da sociedade implica necessariamente que este desenvolvimento seja logrado em função da minimização das diferenças internas, quer regionais, quer individuais pois em um processo social coeso, as partes estão intrinsecamente interligadas, de tal sorte que quando nos preocupamos apenas com as condições urbanas, olvidamos de analisar que boa parte da miséria urbana tem origem no rural. É importante entender que nenhum país é mais desenvolvido do que o seu grupo social mais frágil. E no Brasil, a fragilidade dos grupos sociais é histórica, com a política de exclusão social que foi incentivada em nosso desenvolvimento econômico através de um capitalismo periférico. $\mathrm{O}$ resgate dessa dívida social, passa também pelas ações a serem praticadas através de políticas públicas voltadas para os excluídos, e nesses, para os excluídos do mundo rural, e os psicólogos podem auxiliar no desenho e na avaliação de modelos de atenção em saúde e educação.

Mais ainda, que o crescimento desordenado das grandes cidades gerou um ambiente entrópico no qual por mais que se invistam recursos, a qualidade de vida tende a piorar. Uma possibilidade de solução seria deslocar esses investimentos das grandes para as pequenas cidades, pois ali é mais barato e efetivo o investimento na geração de empregos, segurança e qualidade de vida cidadã. Apenas para ter-se um dado comparativo, enquanto a cidade de São Paulo tem um policial para cada 290 habitantes, em uma cidade pequena, na zona rural esta relação é de um para 3000. E não se pode dizer que o nível de segurança de São Paulo é superior ao de uma pequena cidade.

O resgate da cidadania é um elemento importante tanto do ponto de vista da justiça social, como também do ponto de vista econômico, e isto é o que mais pode chamar a atenção, como condição básica para a alavancagem de um processo de desenvolvimento sustentável. A possibilidade de geração de emprego e renda na zona rural é muito mais rápida, barata e de retorno mais imediato que nos grandes cen- 
tros ou através da agricultura de larga escala. Porém, o importante é que esse processo não se confunda com um investimento a mais e, sim, que seja pautado por uma filosofia que busque a dignidade cidadã como um fim e, ao mesmo tempo, como processo do desenvolvimento sustentável, sendo, portanto, parte de uma política de desenvolvimento nacional, e não um programa de desenvolvimento agrário, como sói acontecer. Aqui o psicológico deve interagir com a economia e a sociologia no planejamento de ações estratégicas de largo alcance.

Neste sentido, as Universidades podem desempenhar um papel importante na medida em que adeqüem seus currículos e voltem parte de suas pesquisas para estudar, entender e posteriormente intervir nesta realidade. Outros campos do saber já fizeram isto. A sociologia tem entre os seus ramos um que se dedica a estudar o rural, a economia também direciona uma parte do seu esforço especificamente para aspectos, será que a psicologia poderia desenvolver estudos nesta direção? A pergunta não respondida é se o faria sob o mesmo paradigma que ora detém, ou se é necessária a construção de um outro. Esta é uma questão em aberto, que demonstra a necessidade de que cursos de pós-graduação voltem seus olhares para esta esfera.

\section{Conclusão: Uma Mudança de Perspectiva}

Por fim, gostaria de chamar a atenção para o fato de que ao analisarmos o rural, devemos ter o cuidado de despojarmonos dos nossos olhos urbanos. $\mathrm{O}$ ambiente bucólico que desde as cidades percebemos quando comparamos uma instância com outra, sofre uma ruptura quando pesquisas indicam que o estresse vivenciado por mulheres na zona rural é maior do que o daquelas que habitam cidades médias, conforme mostram Ayres, Brito e Lipp, (1999). Outrossim, também encontramos resultados que nos indicam serem os aposentados rurais melhor adaptados e psicologicamente mais bem resolvidos que os urbanos (Albuquerque, Lobo \& Raymundo, 1999). E as diferenças entre gêneros? E no que tange às crenças e atitudes dos habitantes das zonas rurais sobre a ecologia e o desenvolvimento sustentável? Também nos parece haver um enorme campo de trabalho e de pesquisas no que se refere à transferência de tecnologia para os agricultores. Afinal de contas, os processos de aprendizagem têm sido um dos pilares de estudo da psicologia. Quanto aos estudos sobre o trabalho, penso que existe um imenso deserto que urge ser preenchido. Segurança e proteção individual contra o uso e aplicações de pesticidas e fungicidas, ergonomia, adestramento de animais, são demandas que podem representar uma fonte de trabalho e de pesquisas muito útil.

É fácil de observar que nós psicólogos, embora detenhamos um vasto conhecimento sobre avaliação do comportamento, pouco nos dedicamos a relacionar estas avaliações com as políticas públicas. Ora, considero que as políticas públicas, em suas mais diversas instâncias, municipais, estaduais e federais, constituem uma espécie de meta-variável independente que afeta a todos nós. Avaliamos suas consequiências, porém poucas vezes enfatizamos esta relação de modo a influir politicamente nas mudanças da estrutura. Neste sentido, diferentemente dos países desenvolvidos, temos uma concepção personalista da riqueza, e não coletiva como os demais (não confundir com individualismo x coletivismo).

Os habitantes dos países desenvolvidos, encontram amparo das instituições públicas no que se refere ao seu bem estar social. Aqui, pela ausência de políticas públicas adequadas, desenvolvemos uma percepção de que os seviços públicos são para os pobres e, portanto, podemos deixá-los sem maiores cuidados. Isto reflete um provincianismo capenga, que tem mostrado, por exemplo, sua face mais perversa na violência com a qual nos deparamos nas grandes cidades brasileiras. Pensar em segurança pública, sem investir nas pequenas cidades de forma atrair os que delas partiram, e a fixar os que nelas querem permanecer, é pensar que polícia mantém segurança sobre vidas. Analisado no seu conjunto, ou desde fora, nenhum país será mais rico que a parcela mais pobre de sua população. Nosso país será sempre tão pobre quanto o mais pobre dos seus cidadãos, será tão pouco desenvolvido quanto menor desenvolvida for a sua região mais miserável, enfim, será tão subdesenvolvido quanto a parte mais subdesenvolvida de seus cidadãos.

O investimento por parte do Estado através de políticas públicas voltadas para a população no que se refere a agilização e acesso da justiça, a segurança cidadã, a melhoria das escolas e a oferta de serviços de saúde pública de qualidade, é condição necessária para darmos o salto em direção a um país mais justo, saudável e educado e conseqüentemente desenvolvido. Deixemos de copiar etiquetas do primeiro mundo, e passemos a analisar os serviços que ofertam aos seus cidadãos, quem sabe assim, possamos aproveitar algo de bom desse atual processo de globalização. No final das contas, a diferença entre um país de primeiro mundo e um de terceiro, não se mede pelas belezas naturais ou pela gente jovem e bonita, e sim pela qualidade de vida de seus cidadãos. Mas, de todos eles!

Enfim, vislumbro a amplitude do campo de atuação que se abre tanto para os profissionais quanto para os pesquisadores que desejam conhecer e intervir mais de perto em nossa realidade, incluindo o ambiente rural e conseqüentemente a análise das políticas públicas, como um objeto de estudo e trabalho da psicologia enquanto área de produção de conhecimento e atuação dos psicólogos.

\section{Referências}

Albuquerque, F.J.B. (2001). Aproximación metodológica desde la psicologiga social a la investigación en zonas rurales. Revista Española de Estudios Agrosociales y Pesqueros. 191, 225 233.

Albuquerque, F.J.B.; Lobo, A L. \& Raymundo, J.S. (1999). Análise das repercussões psicossociais decorrentes da concessão de benefícios rurais. Psicologia: Reflexão e Crítica, 12, 503-519.

Albuquerque, F.J.B. (1997). El impacto de la introdución de un modelo político individualista en una región caracterizada por modelo colectivista. Desastres y Sociedad, La Red, 8, Peru. 


\section{F. J. B. Albuquerque}

Albuquerque, F.J.B. (1996). Aspectos psicossociais das cooperativas agrárias. Em: Trabalho, Organizações e Cultura. Tamayo, A. Borges-Andrade, J. \& Codo, W. (orgs.). Coletâneas da ANPPEP, 11

Albuquerque, F.J.B.; Clemente, M. \& Menezes, S. (1996). Aspectos psicossociais na formação de cooperativas agrárias. Psico, 27, 207-214.

Ayres, K. V.; Brito, S. M. O \& Lipp, M. N. (1999). Stress feminino: um fenômeno possível na cidade e na roça. Em: Olhar multifacetado na saúde. Fernandes, A. G.; Medeiros, J. L. A. \& Brasileiro, M. C. E. (orgs.). Campina Grande: EDUEP.

Bonavigo, E. A (1998). Produção Sócio-Histórica da "Cooperação Agrícola"no Acampamento da Fazenda Annoni e no Assentamento 16 de Março": Práticas Cotidianas e Produções de Subjetividades. Instituto de Psicologia, UFRJ, Dissertação de Mestrado. Rio de Janeiro.

Carvalho, H.M. (1998). Formas de associativismo vivenciadas pelos trabalhadores rurais nas áreas oficiais de reforma agrária no Brasil. Ministério Extraordinário de Política Fundiária., Brasília.

Clemente, M. \& Albuquerque, F. J. B. (1998). Aportes de la psicologia social al desarrollo rural: estudio sobre formación y desarrollo de las cooperativas agrarias. Em: Psicologia del Trabajo: nuevos conceptos, controversias y aplicaciones. Vallejo, R. D. \& Pastor, J. D. V. (Orgs.),. Ed. Pirámide. Madri.

Clemente, M. \& Albuquerque, F.J.B. (1993). Las cooperativas agrarias ante el reto de la Unión Europea: aporte de una psicologia social al desarrollo rural. Sociedad y Utopia, 165-180. Madri, Espanha.

Clemente, M.; Albuquerque, F.J.B. \& Reyes, T. (1993). Análisis del conflicto en el interior de las cooperativas agrarias y estrategias de superación. Madri, Espanha: Fundación Largo Caballero.
Figueiredo, S.M.F. (1995). Análise psicossocial da capacidade de mobilização e das condições internas do movimento dos trabalhadores rurais sem terra em termos de representações e identidades sociais. Dissertação de Mestrado. Universidade Federal da Paraíba. João Pessoa.

Garcia Sanz, B, (1999). La sociedad rural ante el siglo XXI. Ministerio de Agricultura, Pesca y Alimentación, Madrid Espanha.

Ianni, O. (1979). Ditadura e Agricultura. Ed. Civilização Brasileira, Rio de Janeiro.

Ieno Neto \& Bamat, T. (1998). Qualidade de vida e reforma agrária na Paraíba. UNITRABALHO/UFPB.

Instituto Brasileiro de Geografia e Estatística (2002), Anuário Estatístico do Brasil (On line), http://www.ibge.gov.br

Instituto Nacional de Colonização e Reforma Agrária (2002). http:/ /www.incra.gov.br

Lewin, K. (1965). Teoria de campo em psicologia social. Livraria Pioneira Editora. São Paulo

Martin-Baró, I. (1998). Psicologia de la Liberación. Ed. Trotta Madri, Espanha

Mascareño, R.M.P. (1999). A adoção de inovações tecnológicas entre os pequenos agricultores: uma análise psicossocial da extensão rural pública na Paraíba. Dissertação de Mestrado. Universidade Federal da Paraíba. João Pessoa.

Morales, F.; Paez,D., Deschamps, J.C. \& Worchel, 1996. Identidade social. Promolibro, Valencia, Espanha.

Rebollso, E. (1994). Conducta de masa y movimientos colectivos. Em: Psicologia Social. Morales, F.; Moya, M.; Rebolloso, E.; Dols,F.; Huici, C. Marques, J.; Paez,D. \& Perez, J.A. (orgs.). Madri, Espanha.

Ribeiro, D. (1978). Sobre o óbvio. Encontros com a Civilização Brasileira, 9-22, Rio de Janeiro. 